\title{
Cloning, Chromosomal Localization, and RNA Expression of a Human $\beta$ Chemokine Receptor-Like Gene
}

\author{
CHRISTOPHE COMBADIERE, SUNIL K. AHUJA, and PHILIP M. MURPHY
}

\begin{abstract}
$A$ human cDNA encoding a putative $G$ protein-coupled receptor designated chemokine $\beta$ receptor-like 1 (CMKBRL1) was isolated from an eosinophilic leukemia library. Its deduced sequence is $\sim 40 \%$ identical to previously cloned receptors for the $\beta$ chemokines macrophage inflammatory protein-1 $\alpha$ (MIP-1 $\alpha$ ), RANTES, and monocyte chemoattractant protein-1 (MCP-1), which are chemoattractants for blood leukocytes, and is 83\% identical to the product of the orphan rat cDNA RBS 11. Like the MIP-1a/RANTES receptor, CMKBRL1 is encoded by a small, single-copy gene that maps to chromosome 3p21 and is expressed in leukocytes. However, two screening assays with a broad panel of chemokines failed to identify its ligand. CMKBRL1 mRNA was detectable by Northern blot hybridization in neutrophils and monocytes, but not eosinophils, and was also found in eight solid organs that were tested with particularly high expression in brain. The RNA distribution of the known $\beta$ chemokine receptors was overlapping but distinct from that of CMKBRL1. MIP$1 \alpha /$ RANTES receptor mRNA was detectable in neutrophils, monocytes, eosinophils, and in all eight solid organs tested, with particularly high expression in placenta, lung, and liver. MCP-1 receptor mRNA was found in monocytes, lung, liver, and pancreas. These results suggest that the ligand for the putative CMKBRL1 receptor is a $\beta$ chemokine that targets both neutrophils and monocytes. Moreover, the RNA distributions suggest that CMKBRL1, the MIP-1 $\alpha$ /RANTES receptor, and the MCP-1 receptor may have both overlapping and distinct biological roles.
\end{abstract}

\section{INTRODUCTION}

C HEMOKINES ARE A GROUP OF at least 18 structurally related 70 - to 90 -amino-acid polypeptides that regulate the trafficking and activation of mammalian leukocytes (reviewed in Baggiolini et al., 1994). Two subfamilies exist based on the location of the first two of four conserved cysteine residues. For $\alpha$ chemokines, the first two cysteines are separated by a single amino acid (CXC motif), whereas for $\beta$ chemokines they are adjacent (CC motif). Most $\alpha$ chemokines attract neutrophils, whereas $\beta$ chemokines do not. Instead, $\beta$ chemokines attract monocytes, eosinophils, basophils, and lymphocytes with variable selectivity.

cDNAs for four human leukocyte chemokine receptors have been cloned. They include two $\alpha$ chemokine receptors, designated interleukin-8 (IL-8) receptors A and B (78\% overall amino acid identity), and two $\beta$ chemokine receptors, designated the macrophage inflammatory protein- $\alpha$ (MIP-1 $\alpha$ )/RANTES receptor and the monocyte chemoattractant protein-1 (MCP-1) re- ceptor (54\% identity) (Holmes et al., 1991; Murphy and Tiffany, 1991; Gao et al., 1993; Neote et al., 1993; Charo et al., 1994). Both of the $\beta$ chemokine receptors are $\sim 30 \%$ identical in sequence to the $\alpha$ chemokine receptors. All are members of the rhodopsin-like, heptahelical, $\mathrm{G}$ protein-coupled receptor superfamily. Receptors for at least eight known chemokines have not yet been identified. Given the substantial sequence relatedness of the known receptors, we reasoned that novel chemokine receptor cDNAs could be found in leukocyte libraries using common sequence motifs as hybridization probes.

Here we describe the cloning, chromosomal localization and RNA expression of a novel human gene designated chemokine $\beta$ receptor-like 1 (CMKBRL1) encoding a putative protein highly related in sequence to the known $\beta$ chemokine receptors. In addition, we describe the RNA distribution of the MIP$1 \alpha /$ RANTES receptor and the MCP- 1 receptor. All three genes are expressed in peripheral blood-derived monocytes, but differ in their patterns of RNA expression with respect to neutrophils and eight different human solid organs. The sequence

The Laboratory of Host Defenses, National Institute of Allergy and Infectious Diseases, Bethesda, MD 20892. 
and expression pattern for CMKBRL1 suggest that the ligand for its putative encoded receptor will be a $\beta$ chemokine that targets both neutrophils and monocytes.

\section{MATERIALS AND METHODS}

\section{Gene and cDNA cloning}

Construction of a $\lambda$ gtll cDNA library prepared from peripheral blood mononuclear cells of a patient with eosinophilic leukemia has been previously described (Rosenberg et al., 1989). The library was screened by plaque hybridization with seven different degenerate oligonucleotides designed to recognize transmembrane domains 2, 3,6, and 7 of known chemokine receptors. The oligonucleotides were phosphorylated with $\left[\gamma^{32} \mathrm{P}\right] \mathrm{ATP}$ using a DNA $5^{\prime}$ end-labeling kit (BoehringerMannheim, Indianapolis, IN). Plaque lifts were incubated in $10^{6}$ $\mathrm{cpm} /$ probe per $\mathrm{ml}$ of hybridization buffer for $12 \mathrm{hr}$ and then were washed at $55^{\circ} \mathrm{C}$ in $5 \times \mathrm{SSPE}$ for $5 \mathrm{~min}$. Duplicate positive plaques were purified, and inserts were subcloned into the Eco RV site of pBluescript II SK (Stratagene, La Jolla, CA) and sequenced on both strands. Genomic clones corresponding to cDNAs of interest were cloned from a human genomic library in the vector Lambda FIX (Stratagene, La Jolla, CA) screened at low stringency (final wash at $55^{\circ} \mathrm{C}$ in $5 \times \mathrm{SSPE}$ for $30 \mathrm{~min}$ ) with radiolabeled cDNA probes, using materials and methods previously described (Murphy et al., 1992). Genomic organization was analyzed by (i) Southern hybridization of total human genomic DNA cleaved with panels of restriction enzymes according to previously published methods (Murphy et al., 1992), and (ii) by polymerase chain reaction (PCR) using specific sense and antisense 24-nucleotide amplimers. PCR conditions were as follows: denaturation at $95^{\circ} \mathrm{C}$ for $5 \mathrm{~min}$ for one cycle; 35 cycles of denaturation at $95^{\circ} \mathrm{C}$ for $30 \mathrm{sec}$, annealing at $60^{\circ} \mathrm{C}$ for $30 \mathrm{sec}$, and extension at $72^{\circ} \mathrm{C}$ for $1 \mathrm{~min}$; final extension at $72^{\circ} \mathrm{C}$ for $5 \mathrm{~min}$.

\section{RNA analysis}

Total RNA was prepared using an RNA isolation kit (Stratagene, La Jolla, CA) from human peripheral blood neutrophils isolated by Hypaque-Ficoll differential centrifugation (>95\% neutrophils), from human blood monocytes separated from lymphocytes by adherence to plastic for $18 \mathrm{hr}$, and from human blood eosinophils isolated from a healthy individual with a $>10$ year history of stable hypereosinophilia (>99\% eosinophils) as previously described (Ahuja et al., 1994). RNA samples were fractionated by size by denaturing gel electrophoresis, ethidium-stained to ensure equivalent loading, blotted to nylon membranes (MSI, Westboro, MA) in $10 \times \mathrm{SSC}$, and hybridized to cDNA probes labeled to similar specific activity with $\left[\alpha_{-}{ }^{32} \mathrm{P}\right] \mathrm{dCTP}$ using a random primer labeling kit (Boehringer-Mannheim). The cDNA probes were for: CMKBRL1, a $1.5-\mathrm{kb}$ cDNA reported in the present paper; MIP$1 \alpha /$ RANTES receptor, a $2.6-\mathrm{kb}$ cDNA reported in Gao et al. (1993); MCP-1 receptor, a 1.5-kb cDNA containing the entire ORF of MCP-1 receptor type B (Combadiere et al., manuscript in preparation); and human $\beta$-actin, a 2 -kb cDNA (Clontech). Membranes were incubated with $10^{6} \mathrm{cpm} / \mathrm{ml}$ of hybridization buffer for $18 \mathrm{hr}$ and then washed. A blot containing total RNA from a panel of human organs was purchased from Clontech (Palo Alto, CA). After each hybridization, blots were washed in $50 \%$ formamide $/ 6 \times \mathrm{SSPE}$ at $70^{\circ} \mathrm{C}$ for $30 \mathrm{~min}$ to remove the probe.

\section{Creation of stably transfected cell lines}

cDNA was subcloned between the Nhe I and Xho I sites of the mammalian expression vector pREP9 (Invitrogen, San Diego, CA). Human K562 erythroleukemia and adenovirustransformed human embryonic kidney 293 cells $\left(10^{7}\right)$ in $\log$ phase were transfected by electroporation, with $20 \mu \mathrm{g}$ of plasmid DNA and selected with G418, as previously described (Gao and Murphy, 1994).

\section{Ligand binding analysis}

After washing in phosphate-buffered saline (PBS), $10^{6}$ transfected cells were incubated in duplicate with 0.1 or $0.5 \mathrm{n} M{ }^{125} \mathrm{I}$ labeled IL-8, GRO $\alpha$, RANTES, MCP-1, MIP- $1 \alpha$, or MIP-1 $\beta$ (sp. act., $\sim 2,200 \mathrm{Ci} / \mathrm{mmole}$, Du Pont/New England Nuclear, Boston, MA) and varying concentrations of unlabeled recombinant human chemokines (Peprotech, Rocky Hill, NJ) in binding medium consisting of RPMI-1640 with $1 \mathrm{mg} / \mathrm{ml}$ bovine serum albumin (BSA) and $25 \mathrm{~m} M$ HEPES pH 7.4 in a total volume of $200 \mu \mathrm{l}$. Specific binding was determined in the presence of 1,000-fold excess of unlabeled chemokine. Control binding was performed on purified human leukocytes and/or K562 cells stably transfected with the human MIP- $1 \alpha /$ RANTES receptor and human IL-8 receptor B. After incubation for 1.5 hr at $4^{\circ} \mathrm{C}$, the cells were pelleted through a $10 \%$ sucrose/PBS cushion and specific binding was determined.

\section{Intracellular $\left[\mathrm{Ca}^{2+}\right]$ measurements}

Cells $\left(10^{7} / \mathrm{ml}\right)$ were incubated in Hank's buffered saline solution with $\mathrm{Ca}^{2+}$ and $\mathrm{Mg}^{2+}$ supplemented with $10 \mathrm{mM}$ HEPES pH 7.4 (HBSS), and containing $2.5 \mu M$ FURA-2 AM (Molecular Probes, Eugene, OR) for $60 \mathrm{~min}$ at $37^{\circ} \mathrm{C}$ in the dark. The cells were subsequently washed twice with HBSS, and resuspended at $2 \times 10^{6}$ cells $/ \mathrm{ml}$. Two milliliters of the cell suspension were placed in a continuously stirred cuvette at $37^{\circ} \mathrm{C}$ in a fluorimeter (Photon Technology Inc., South Brunswick, $\mathrm{NJ})$. Fluorescence was monitored at $\lambda_{\mathrm{ex} 1}=340 \mathrm{~nm}, \lambda_{\mathrm{ex} 2}=380$ $\mathrm{nm}$, and $\lambda_{\mathrm{em}}=510 \mathrm{~nm}$, during stimulation with test substances. Cultured human monocyte and osteosarcoma cell line supernatants, respectively, were generously supplied by J. Van Damme.

All chemokines tested, except for mouse TCA3, were recombinant human proteins. Mig, platelet factor 4, I-309, and TCA3 were generous gifts of J. Farber, G. LaRosa, M. Krangel, and M. Dorf, respectively. IL-8, GRO $\alpha$, GRO $\beta$, IP-10, MIP$1 \alpha$, MIP- $1 \beta$, MCP-1, MCP-2, MCP-3, and RANTES were purchased from Peprotech (Rocky Hill, NJ). NAP-2 was from Bachem (Philadelphia, PA). C3a was a gift of C. Hammer. fMLP and recombinant human C5a were purchased from Sigma (St. Louis, MO). The data were recorded as the relative ratio of fluorescence excited at 340 and $380 \mathrm{~nm}$. Data were collected every $200 \mathrm{msec}$. 
Chromosomal localization by fluorescence in situ hybridization

Purified DNA from the phage clone containing an 18-kb genomic insert was labeled with biotin dUTP by nick translation (BIOS, New Haven, CT). Labeled probe was combined with sheared human DNA and hybridized to normal metaphase chromosomes derived from PHA-stimulated peripheral blood lymphocytes in a solution containing $50 \%$ formamide, $10 \%$ dex- tran sulfate, and $2 \times$ SSC. Specific hybridization signals were detected by incubating the hybridized slides in fluoresceinated avidin. Following signal detection, the slides were counterstained with propidium iodide and analyzed.

\section{RESULTS}

Out of 49 positive cDNA clones isolated from the eosinophilic leukemia library, 44 encoded the MIP-1 $\alpha$ /RANTES receptor,

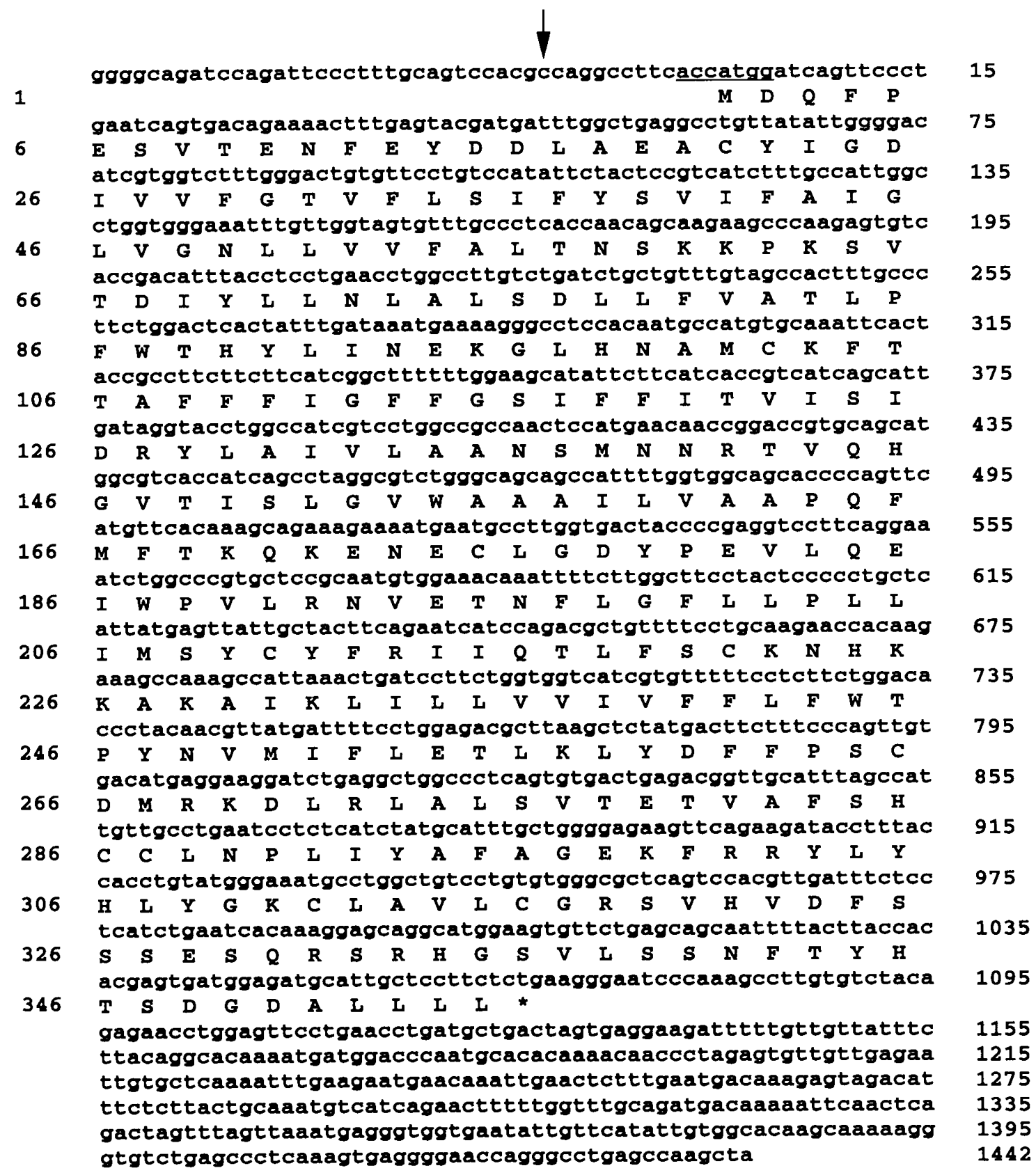

FIG. 1. Nucleotide and deduced amino acid sequence of CMKBRL1 cDNA. The final nucleotide in each row is enumerated at the right relative to the $\mathrm{A}$ in the first codon, which is defined as position +1 . The first amino acid in each row is enumerated at the left. The underlined sequence identifies the predicted ATG initiation site and flanking sequences that conform to the consensus sequence for translation initiation sites (Kozak, 1984). The arrow indicates the location of an intron-exon boundary. The sequences have been deposited in GenBank (accession number U28934). 


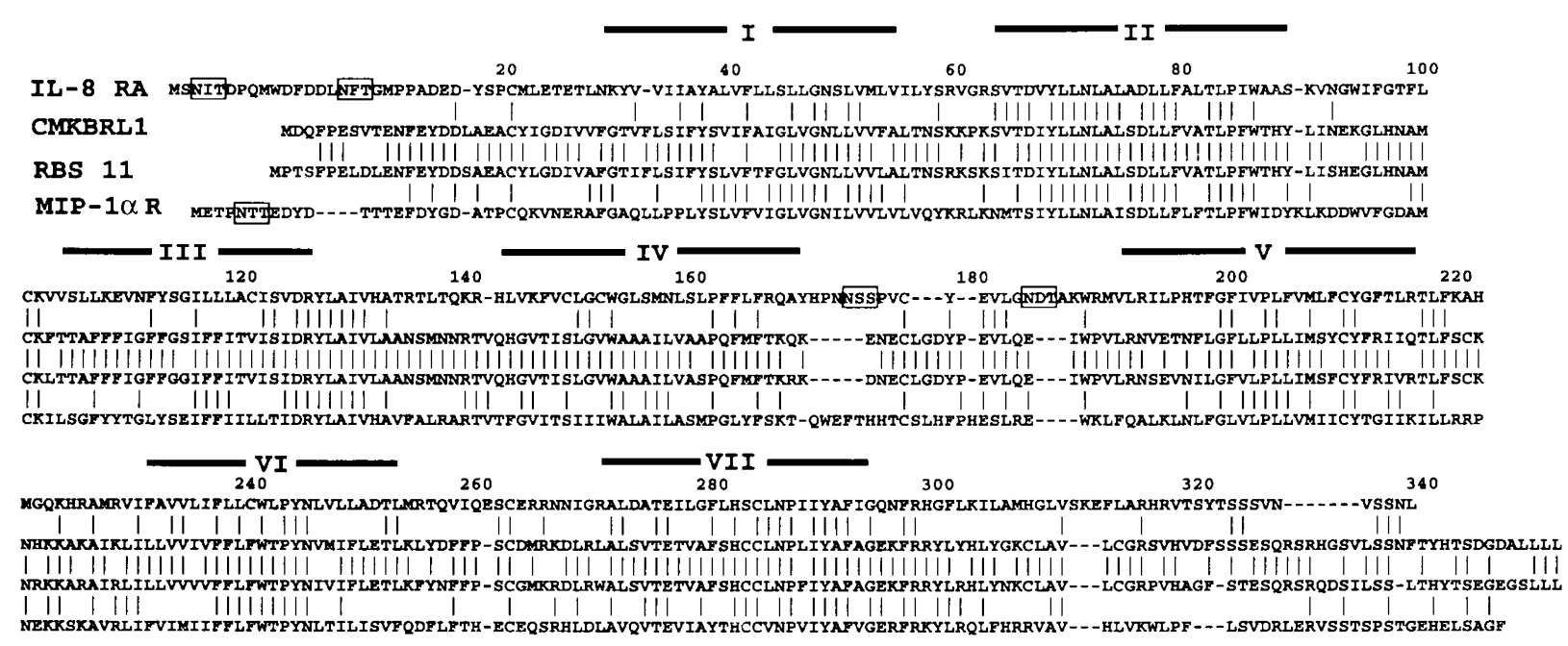

FIG. 2. Alignment of amino acid sequences deduced from cDNAs for CMKBRL1, RBS11, the human MIP-1 $\alpha$ /RANTES receptor (MIP-1 $\alpha$ R) and the human IL-8 receptor type A (IL-8 RA). Vertical bars indicate identical residues for each adjacent sequence position. Arabic numbers enumerate the CMKBRL1 sequence and are left-justified. Dashes indicate gaps that were inserted to optimize the alignment. The location of predicted membrane-spanning segments I-VII are noted. Open boxes designate predicted sites for $N$-linked glycosylation.

one was for an IL-8 receptor, one was for the MCP-1 receptor, and three were novel. The first of these novel cDNAs was designated CMKBRL1 for chemokine $\beta$ receptor-like 1. CMKBRL1 is 1,487 bp long (Fig. 1). The longest open reading frame (ORF) contains 1,110 nucleotides beginning at the first nucleotide of the cDNA. Within this ORF, the first methionine-encoding ATG codon begins at nucleotide number 46 . Its sequence context, ACC ATGG, conforms well to the Kozak consensus criteria for translation initiation sites which is strongly biased in favor of $A$ at position -3 and $G$ at position +1 relative to the ATG (Kozak, 1984). For this reason, we predict that the $5^{\prime}$ untranslated region (UTR) of CMKBRL1 is at least 45 bp in length, whereas the protein-encoding portion of the ORF and the $3^{\prime}$ UTR are 1,065 and at least $377 \mathrm{bp}$, respectively. A poly (A) ${ }^{+}$ tail and signal are absent. The ORF encodes a predicted protein of 355 amino acids (Fig. 1).

Sequence analysis suggests that this putative receptor is the human ortholog of a previously described orphan receptor predicted from a cloned rat cDNA designated RBS11 (83\% amino acid identity) (Harrison et al., 1994) (Fig. 2). A data base search using the FASTA algorithm of the University of Wisconsin Genetics Computer Group (GCG, Devereux et al., 1984) revealed that its deduced amino acid sequence is most similar to the known leukocyte $\beta$ chemokine receptors (42\% identity with the human MIP-1 $\alpha$ /RANTES receptor; $40 \%$ identity with the human MCP-1 receptor), with somewhat less similarity to the $\alpha$ chemokine receptors ( $\sim 30 \%$ identity with the IL- 8 receptors). The alignment is strongest in the regions predicted by hydropathy analysis to represent transmembrane domains for chemokine receptors (Murphy, 1994). These regions have significant sequence conservation with other rhodopsin-like $\mathrm{G}$ protein-coupled receptors (Probst et al., 1992). Like all other known chemokine receptors, and unlike most other types of $G$ protein-coupled receptors, the CMKBRLl sequence is highly acidic in the amino-terminal segment before the first putative transmembrane domain, containing a net charge of -8 , and has conserved cysteine residues in the amino-terminal segment and the third predicted extracellular loop (Murphy, 1994).

Two sequence features conserved in known chemokine receptors are absent in CMKBRL1 and RBS11. First, a prolinecysteine motif found in the amino-terminal segment of the chemokine receptors aligns with alanine-cysteine in the CMKBRL1 sequence. Second, CMKBRL1 lacks a consensus sequence for $N$-linked glycosylation that is found in chemokine receptors and most other $\mathrm{G}$ protein-coupled receptors.

Hybridization of the CMKBRL1 cDNA to total human genomic DNA digested with Pst I, Xba I, and Hind III revealed one hybridizing band in each case, whereas Eco RI gave two smaller bands of lighter intensity (Fig. 3A). The cDNA lacks sites for cleavage by these four enzymes. This hybridization pattern is most consistent with a small, single-copy gene. The two Eco RI bands may represent polymorphisms of the same gene. A genomic clone corresponding to CMKBRL1 was then isolated and a 4-kbp Pst I fragment subcloned. PCR amplification of the cloned cDNA and gene for CMKBRL1 using a $5^{\prime}$ amplimer at the start of the ORF and a $3^{\prime}$ amplimer located within the $3^{\prime}$-UTR each gave a $1.6-\mathrm{kb}$ product identical in size to that obtained using total human genomic DNA as the template, suggesting the absence of introns in the coding region and at least this portion of the $3^{\prime}$-UTR (Fig. 3B). This was confirmed by direct DNA sequencing of the genomic Pst I fragment. The genomic and cDNA sequences diverge $5^{\prime}$ to nucleotide -13 , suggesting the presence of an intron in the 5 '-UTR. This is consistent with the genomic organization of the IL- 8 receptors and the MIP- $1 \alpha /$ RANTES receptor, which all contain at least one intron in the 5'-UTR (Ahuja et al., 1992, 1994; Gao et al., unpublished data). An Eco RI site was not found in the ORF of the CMKBRL1 genomic clone. Thus, the 


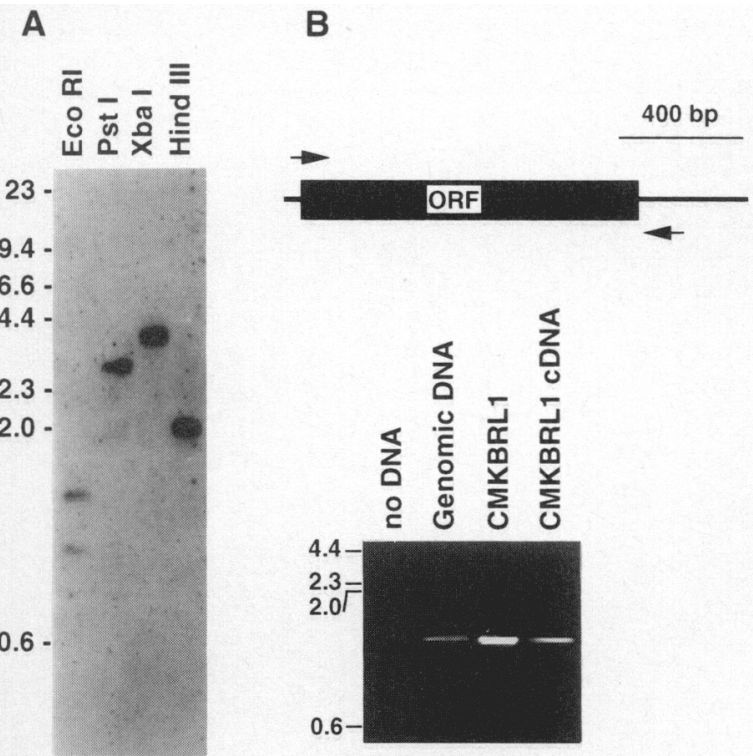

FIG. 3. Analysis of the CMKBRL1 gene. A. Restriction enzyme analysis. Total human genomic DNA $(5 \mu \mathrm{g})$ was digested with the restriction enzymes indicated at the top of each lane, gel-fractionated, and blot-hybridized with the CMKBRL1 cDNA. The blot was washed at $65^{\circ} \mathrm{C}$ in $0.2 \times$ SSPE for $1 \mathrm{hr}$ and then exposed to XAR-2 film with an intensifying screen. B. CMKBRL1-specific primers were used in PCR reactions containing no DNA, total human genomic DNA, a plasmid containing a 4-kb Pst I fragment of a CMKBRL1 genomic clone, or the CMKBRL1 cDNA, and the products visualized after electrophoresis through a $0.8 \%$ agarose gel containing ethidium bromide. Size markers are indicated in kilobases at the left.

two human genomic DNA Eco RI bands detected by Southern hybridization with the CMKBRL1 probe may represent a restriction fragment length polymorphism of the same gene.

By fluorescence in situ hybridization, the CMKBRL1 genomic phage clone specifically labeled the short arm of a group A chromosome, the size and morphology of which were consistent with chromosome 3. A second experiment was performed in which a chromosome 3 centromere-specific probe was cohybridized with the phage clone. This experiment resulted in the specific labeling of the centromere and the short arm of chromosome 3, segment p21 (Fig. 4). The MIP-1 $\alpha /$ RANTES receptor has been previously localized to the same band, whereas the known $\alpha$ chemokine receptors colocalize to 2q34-q35 (Ahuja et al., 1992; Gao et al., 1993). The chromosomal locus for the MCP-1 receptor has not yet been reported. A third $\beta$ chemokine receptorlike gene designated GPR5 has been cloned that also maps to 3 p21. Its putative product is $44 \%$ identical in amino acid sequence to the MIP-1 $\alpha /$ RANTES receptor and $32 \%$ identical to the MCP1 receptor (Heiber et al., 1995).

If CMKBRL1 encodes a chemokine receptor, it is likely to be expressed in one or more types of blood leukocytes. A single size class $(\sim 3.4 \mathrm{~kb})$ of CMKBRL1 mRNA was detected in similar amounts in human peripheral blood-derived neutrophils and monocytes (Fig. 5). The neutrophil band was slightly larger than the monocyte band. CMKBRL1 mRNA was not detectable in eosinophil samples.

We then compared this result with the expression patterns in
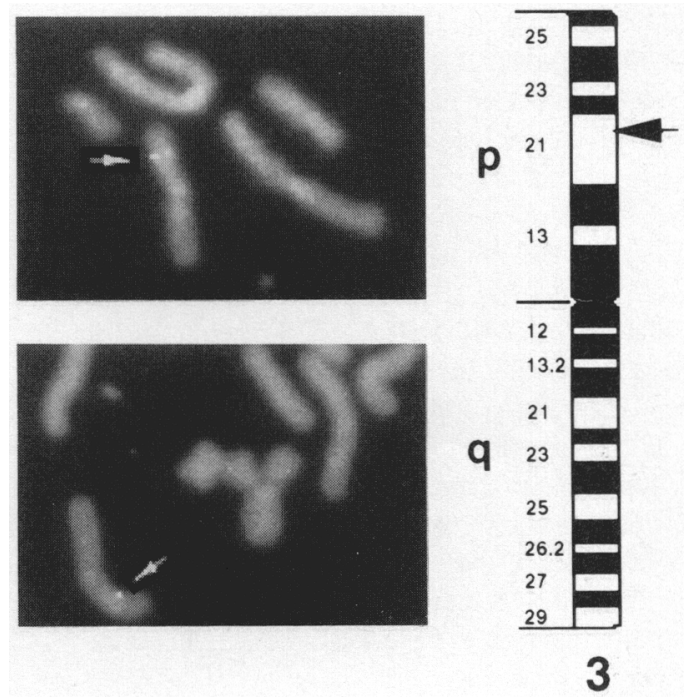

FIG. 4. Chromosomal localization of the CMKBRL1 gene to 3 p21 by fluorescence in situ hybridization. The two representative partial metaphases shown at the left are from an experiment using the CMKBRL1 gene as a probe. A total of 80 metaphase cells were examined with 60 exhibiting specific labeling. Measurements of 10 specifically labeled chromosomes 3 demonstrated that the CMKBRL1 gene is located at a position which is $60 \%$ of the distance from the centromere to the telomere of chromosome arm $3 p$, an area that corresponds to band 3p21 (arrow). An ideogram of G-banding patterns of human chromosome 3 is shown at the right. The arrow points to the hybridization site at 3p21 for CMKBRL1.

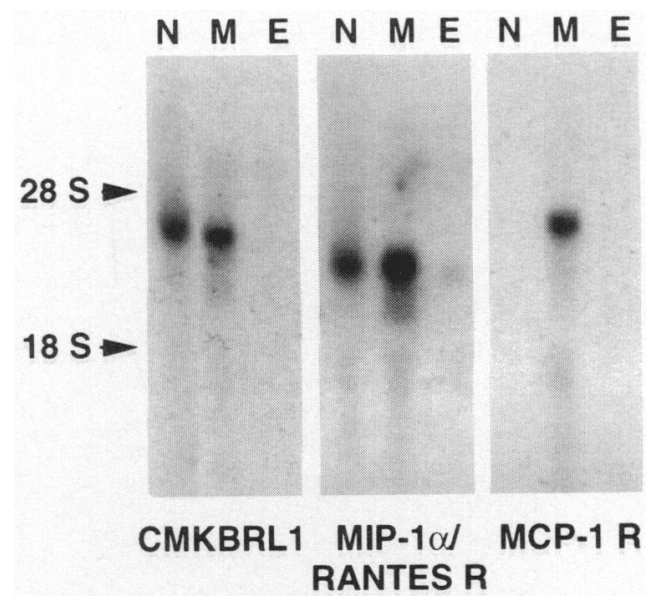

FIG. 5. Analysis of CMKBRL1 and $\beta$ chemokine receptor transcripts in human leukocytes. The same Nytran blot containing $10 \mu \mathrm{g}$ of total RNA from peripheral blood-derived human neutrophils (N), monocytes (M), and eosinophils (E) was hybridized separately with cDNA probes containing the complete ORF for the receptors indicated at the bottom of each panel. The blot was washed in each case at $65^{\circ} \mathrm{C}$ in $0.2 \times$ SSPE for $1 \mathrm{hr}$, then exposed to XAR-2 film with an intensifying screen at $-80^{\circ} \mathrm{C}$ for 5 days (CMKBRL1), 2 days (MCP-1 receptor), and 6 days (MIP-1 $\alpha /$ RANTES receptor). The position of ribosomal bands is indicated at the left. In a control hybridization, the eosinophil RNA contained abundant message for the $N$ formylpeptide receptor (not shown). 
normal blood leukocytes for the known $\beta$ chemokine receptors. The MIP- $1 \alpha /$ RANTES receptor mRNA has previously been shown to be expressed in human peripheral blood-derived neutrophils, monocytes (adherent mononuclear cells), and lymphocytes (nonadherent mononuclear cells), as well as in Staphylococcus aureus Cowan strain-activated tonsillar B cells (Gao et al., 1993; Nomura et al. 1993). Expression in several cultured cell lines has also been reported. We confirmed that a single size class of MIP- $1 \alpha /$ RANTES receptor mRNA $\sim 3.0 \mathrm{~kb}$ in length is present in neutrophils and monocytes (Fig. 5). Monocyte expression appeared to be greater than neutrophil expression. Very small amounts of this RNA were also detectable in eosinophils after prolonged exposures of the blot (Fig. 5). This is consistent with the weak agonist activity of MIP- $1 \alpha$ for eosinophils and further supports the existence of a distinct eosinophil RANTES receptor first proposed by Baggiolini and Dahinden. In contrast to CMKBRL1, the MIP- $1 \alpha$ RANTES receptor band appeared to be the same size in all three cell types tested. MCP-1 receptor mRNA expression has been previously reported only for the cultured cell lines MonoMac 6 and THP1 (Charo et al., 1994). We detected a single size class of MCP1 receptor mRNA, $\sim 3.5 \mathrm{~kb}$, in monocyte samples but not in neutrophil or eosinophil samples.

We next compared the mRNA expression in solid organs for CMKBRL1 and the $\beta$ chemokine receptors (Fig. 6). Unique tissue-specific expression patterns were apparent for each of the thiee genes. CMKBRL1 mRNA was detectable in all eight tissues tested, but appeared to be most abundant in brain. The RNA distribution of CMKBRL1 is consistent with that previously reported in solid organs for its rat ortholog RBS11. However, the expression of RBS11 in rat leukocytes has not been reported (Harrison et al., 1994). MIP-1 $\alpha /$ RANTES receptor mRNA was also detected in all eight tissues tested, but

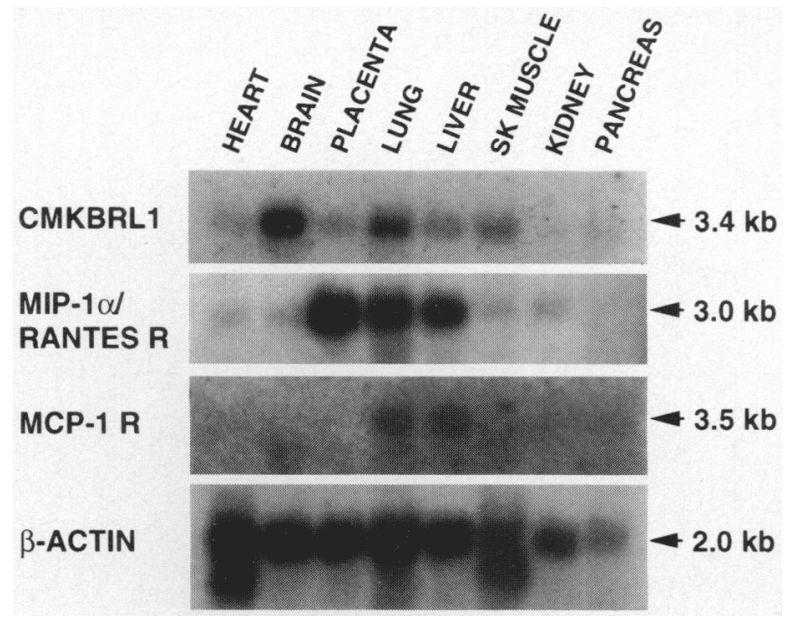

FIG. 6. Analysis of CMKBRL1 and $\beta$ chemokine receptor transcripts in human solid organs. The same blot containing 10 $\mu \mathrm{g}$ of total RNA from the solid human organs indicated at the top of each lane was hybridized separately with the radiolabeled cDNA probes indicated at the left of each panel. The blot was washed exactly as described in Fig. 4, and exposed to XAR2 film for 8 days (CMKBRL1), 5 days (MCP-1 receptor), 5 days (MIP-1 $\alpha /$ RANTES receptor), and $4 \mathrm{hr}(\beta$-actin). The four separate hybridizations of the blot shown were performed in chronological order from top to bottom. The approximate sizes of the bands are indicated at the right of each panel.
Table 1. Summary of the Functional Analysis of the Putative CMKBRL1 Product

\begin{tabular}{|c|c|c|c|}
\hline Ligand & $\mathrm{Ca}^{2+}$ flux & $\begin{array}{l}\text { Radioligand } \\
\text { binding }\end{array}$ & Control $^{\mathrm{a}}$ \\
\hline \multicolumn{4}{|c|}{$\alpha$ Chemokines } \\
\hline IL-8 & - & - & 1,2 \\
\hline $\mathrm{GRO} \alpha$ & - & - & 1,2 \\
\hline GRO $\beta$ & - & ND & 1 \\
\hline PF-4 & - & ND & ND \\
\hline NAP-2 & - & ND & 1 \\
\hline$\gamma$ IP- 10 & - & ND & 1 \\
\hline Mig & - & ND & 1 \\
\hline \multicolumn{4}{|c|}{$\beta$ Chemokines } \\
\hline MIP-1 $\alpha$ & - & - & 1,2 \\
\hline MIP- $1 \beta$ & - & - & 1,2 \\
\hline RANTES & - & - & 1,2 \\
\hline MCP-1 & - & - & 1,2 \\
\hline MCP-2 & - & ND & ND \\
\hline MCP-3 & - & ND & 1 \\
\hline I-309 & - & ND & ND \\
\hline \multicolumn{4}{|l|}{ Others } \\
\hline $\mathrm{C} 3 \mathrm{a}$ & - & ND & 1 \\
\hline $\mathrm{C} 5 \mathrm{a}$ & - & ND & 1 \\
\hline SN1 & - & ND & 1 \\
\hline $\mathrm{SN} 2$ & - & ND & 1 \\
\hline
\end{tabular}

Abbreviations: IL-8, interleukin-8; MIP, macrophage inflammatory protein; MCP, monocyte chemoattractant protein; RANTES, regulated upon activation normal $T$ expressed and secreted; GRO, growth-related gene product; NAP-2, neutrophil-activating protein-2; Mig, monokine inducible by interferon- $\gamma, \quad \gamma \mathrm{IP}-10$, interferon- $\gamma$-inducible protein-10; PF-4, platelet factor 4; ND, not done. SN1 and SN2, cultured human monocyte and osteosarcoma cell line supernatants.

${ }^{\text {a }}$ The activity of each indicated ligand was determined by measuring their ability to mobilize calcium (1) or to bind specifically (2) to human leukocytes and mammalian cell transfectants expressing chemoattractant receptors. All recombinant human chemokines were tested at $100 \mathrm{n} M$ except for Mig and I-309, which were $20 \mathrm{nM}$. C3a and C5a were tested at 100 and $30 \mathrm{n} M$, respectively. Each radioligand was tested at both 0.1 $\mathrm{n} M$ and $0.5 \mathrm{n} M$ in the presence and absence of 1,000 -fold excess unlabeled ligand.

in contrast to CMKBRL1 was much more abundant in placenta, lung, and liver samples than in heart, brain, skeletal muscle, kidney, or pancreas. MCP-1 receptor mRNA was clearly detectable only in lung and liver samples. A very faint band could be detected in pancreas. Since all of the probes used were labeled to a similar specific activity and were used to probe the exact same blots, it is reasonable to conclude that the receptor RNAs are present in low levels compared to $\beta$-actin, which was easily detectable after short exposures of the hybridized blot (Fig. 6).

To attempt to identify the ligand for the putative CMKBRL1 receptor, K562 and 293 cell lines were stably transfected with pREP9 plasmids containing the CMKBRL1 cDNA, and the transfectants were used to screen a broad panel of 16 different human chemokines as well as purified nonchemokine chemoattractants and crude supernatants from activated monocytes and osteosarcoma cells in binding and/or signal transduction assays. Neither cell line acquired sensitivity to any of the ligands tested (Table 1) as assessed by changes in fluorescence in transfec- 
tants loaded with the calcium sensitive dye FURA-2. All of the cloned leukocyte chemokine receptors link to calcium-mobilizing signal transduction processes when expressed in at least one of these cell types (Murphy, 1994). K562 cells transfected with the CMKBRL1 cDNA did not bind any of the six radiolabeled chemokines that were tested (IL-8, GRO $\alpha$, MIP-1 $\alpha$, MIP-1 $\beta$, MCP-1, and RANTES). The transfected cells expressed the recombinant 2-kb CMKBRL1 mRNA, but not the natural 3.4-kb CMKBRL1 transcript. Untransfected K562 cells did not contain detectable transcripts for CMKBRL1 (Fig. 7). As a control, pREP9 plasmid constructs for IL-8 receptor $B$ and the MIP- $1 \alpha /$ RANTES receptor were used to create stable K562 and 293 cell transfectants for which specific binding of and calcium mobilization by the appropriate ligands was demonstrated (not shown). We have also tested Xenopus oocytes microinjected with cRNA for CMKBRL1 but could not demonstrate a calcium release response to any of the ligands in our screening panel. Finally, K562 cells transiently transfected with the CMKBRL1 expression plasmid failed to acquire a calcium flux response to chemokines in the panel.

\section{DISCUSSION}

In this report, we have described a novel human gene on chromosome 3p21, designated CMKBRL1, that is likely to encode a $\beta$ chemokine receptor. The evidence for this is the concordance of its deduced amino acid sequence, chromosomal location and RNA distribution pattern with the known $\beta$ chemokine receptors, and the relative or absolute discordance of these features with those of the known $\alpha$ chemokine receptors.

The distribution of RNA for the MIP-1 $\alpha /$ RANTES receptor and the MCP-1 receptor in neutrophils and monocytes shown

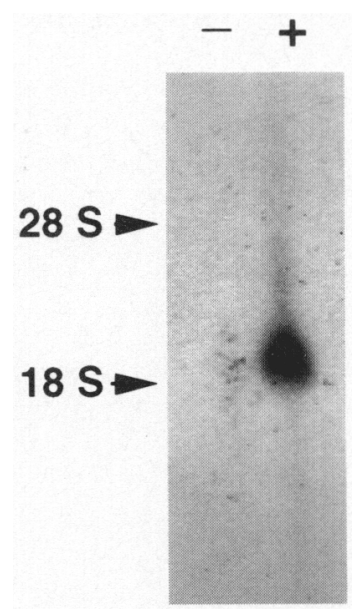

FIG. 7. Expression of CMKBRL1 mRNA in a stably transfected K562 cell line. Total RNA $10 \mu \mathrm{g}$ from untransfected K562 cells (lane -) and K562 cells stably transfected with a pREP9- CMKBRL1 plasmid (lane + ) was probed by Northern blot hybridization with the radiolabeled CMKBRL1 cDNA. The blot was washed as in Figs. 5 and 6. Ribosomal RNA positions are indicated at the left. As expected, the size of the CMKBRL1 transcript in the transfected cells corresponded to the size of the cDNA insert plus the SV40 poly(A) cassette. It was $\sim 1 \mathrm{~kb}$ smaller than the natural CMKBRL1 mRNA (see Figs. 5 and 6). in Fig. 5 is consistent with the responsiveness of these cells to the corresponding chemokines (Gao et al., 1993; McColl et al., 1993). By analogy, detection of CMKBRL1 RNA in similar amounts in neutrophils and monocytes strongly suggests that its putative ligand is an agonist for both cell types. Of the known chemokines, only MIP- $1 \alpha$, RANTES, and TCA3 have this property, but all were inactive in binding and/or signaling experiments with the CMKBRL1-transfected cell lines. No other ligands in a fairly large screening panel were active. The correct ligand could have been missed in our panel if (i) CMKBRL1 does not couple to calcium-mobilizing signal transduction processes, (ii) the correct ligand was one that we could not test in direct radioligand binding assays, (iii) the putative CMKBRL1 protein is not correctly folded or trafficked to the plasma membrane in heterologous cell types, or (iv) the level of expression and/or the ligand binding affinity of the putative CMKBRL1 protein in the heterologous cell types used fell below the limit of detectability of our assays.

The third of the above possibilities might be expected to occur if the natural initiating codon for methionine were 5 to the start of the CMKBRL1 cDNA that we have cloned. This is possible because the ORF can be extended in frame from the predicted ATG initiator to the start of the CMKBRL1 cDNA without encountering a stop codon or methionine. If the true initiator is really $5^{\prime}$ to the start of the known CMKBRL1 cDNA sequence, the coding sequence would necessarily reside on two exons, because an intron-exon boundary is present at nucleotide -13 relative to the ATG initiator assigned in Fig. 1. Because no other chemokine receptor genes have their coding sequences organized in this way, and because the assigned initiation codon possesses flanking sequence that matches the consensus criteria for translation initiation sites, we do not favor this possibility, but instead believe that the assigned initiator is the natural initiator.

Although we have so far been unable to identify the ligand for CMKBRL1, the differential tissue-specific distribution of its RNA and those of the MIP- $1 \alpha /$ RANTES receptor and the MCP-1 receptor is an important new finding that suggests the corresponding receptors may have specialized roles in specific organs. The best example of this is for the placenta, which contains relatively large amounts of RNA for the MIP$1 \alpha /$ RANTES receptor, relatively little for CMKBRL1, and none that is detectable for the MCP-1 receptor. Because all three genes are expressed in blood monocytes, the differential solid organ RNA patterns are unlikely to be due to RNA in blood leukocytes traversing the organ. The observed patterns indicate that both coordinated and differential factors must exist to regulate the expression of these genes. Additional work will be needed to identify these factors and to delineate the precise cell types that account for the RNA signals in solid organs. Tissue leukocytes such as resident macrophages are clearly the best candidates.

The sequence relationships that we have described indicate that an ancestral $\beta$ chemokine receptor gene replicated at least three times. Because at least three of the progeny genes (CMKBRL1, GPR5, and the MIP-1 $\alpha /$ RANTES receptor) map to chromosome 3p21, this region may be a good place to look for genes for other $\beta$ chemokine receptors that have been defined biochemically or functionally (for review, see Baggiolini and Dahinden, 1994; Murphy, 1994). The present molecular analysis strongly suggests that the human $\beta$ chemokine receptor fam- 
ily contains at least one additional member, CMKBRL1. Future studies will be directed toward identifying its ligand and delineating its biological function in the tissues and cell types where it is expressed.

\section{ACKNOWLEDGMENTS}

The authors thank H.F. Rosenberg for providing the eosinophilic leukemia cDNA library, S. Mawhorter for providing purified eosinophils, and $\mathrm{H}$. Lee Tiffany for excellent technical assistance.

\section{REFERENCES}

AHUJA, S.K., OZCELIK, T., MILATOVITCH, A., FRANCKE, U., and MURPHY, P.M. (1992). Molecular evolution of the interleukin8 receptor gene cluster. Nature Genet. 2, 31-36.

AHUJA, S.K., SHETTY, A., TIFFANY, H.L., and MURPHY, P.M. (1994). Comparison of the genomic organization and promoter function for human interleukin-8 receptors A and B. J. Biol. Chem. 269, 26381-26389.

BAGGIOLINI, M., and DAHINDEN, C.A. (1994). CC chemokines and allergic inflammation. Immunol. Today 15, 127-133.

BAGGIOLINI, M., DEWALD, B., and MOSER, B. (1994). Interleukin8 and related chemotactic cytokines- $\mathrm{CXC}$ and $\mathrm{CC}$ chemokines. Adv. Immunol. 55, 97-179.

CHARO, I.F., MYERS, S.J., HERMAN, A., FRANCI, C., CONNOLLY, A.J., and COUGHLIN, S.R. (1994). Molecular cloning and functional expression of two monocyte chemoattractant protein 1 receptors reveals alternative splicing of the carboxyl-terminal tails. Proc. Natl. Acad. Sci. USA, 91, 2752-2756.

DEVEREUX, J., HAEBERLI, P., and SMITHIES, O. (1984). A comprehensive set of sequence analysis programs for the VAX. Nucleic Acids Res. 12, 389-395.

GAO, J.-L., and MURPHY, P.M. (1994). Open reading frame US28 of human cytomegalovirus encodes a functional $\beta$ chemokine receptor. J. Biol. Chem. 269, 28539-28542.

GAO, J.-L., KUNHS, D.B., TIFFANY, H.L., MCDERMOTT, D., LI, X., FRANCKE, U., and MURPHY, P.M. (1993). Structure and functional expression of the human macrophage inflammatory protein$1 \alpha /$ RANTES receptor. J. Exp. Med. 177, 1421-1427.

HARRISON, J.K., BARBER, C.M., and LYNCH, K.R. (1994). cDNA cloning of a G-protein-coupled receptor expressed in rat spinal cord and brain related to chemokine receptors. Neurosci. Lett. 169, 85-89.

HEIBER, M., DOCHERTY, J.M., SHAH, G., NGUYEN, T., CHENG, R., HENG, H.H.Q., MARCHESE, A., TSUI, L.-C., SHI, X.,
GEORGE, S.R., and O'DOWD, B.F. (1995). Isolation of three novel human genes encoding $\mathrm{G}$ protein-coupled receptors. DNA Cell Biol. 14, 25-35.

HOLMES, W.E., LEE, J., KUANG, W.-J., RICE, G.C., and WOOD, W.I. (1991). Structure and functional expression of a human interleukin-8 receptor. Science 253, 1278-1280.

KOZAK, M. (1984). Compilation and analysis of sequences upstream from the translational start site in eukaryotic mRNAs. Nucleic Acids Res. 12, 857-872.

MCCOLL, S.R., HACHICHA, M., LEVASSEUR, S., NEOTE, K., and SCHALL, T.J. (1993). Uncoupling of early signal transduction events from effector function in human peripheral blood neutrophils in response to recombinant macrophage inflammatory proteins- $1 \alpha$ and -1ß. J. Immunol. 150, 4550-4560.

MURPHY, P.M. (1994). The molecular biology of leukocyte chemoattractant receptors. Annu. Rev. Immunol. 12, 593-633.

MURPHY, P.M., and TIFFANY, H.L. (1991). Cloning of complementary DNA encoding a functional interleukin- 8 receptor. Science 253, $1280-1283$.

MURPHY, P.M. OZCELIK, T., KENNEDY, R.T., TIFFANY, H.L., MCDERMOTT, D., and FRANCKE, U. (1992). A structural homologue of the human $N$-formyl peptide receptor. Characterization and chromosome mapping of a peptide chemoattractant receptor family. J. Biol. Chem. 267, 7637-7643.

NEOTE, K., DIGREGORIO, D., MAK, J.Y., HORUK, R., and SCHALL, T.J. (1993). Molecular cloning, functional expression, and signaling characteristics of a C-C chemokine receptor. Cell $\mathbf{7 2 ,}$ 415-425.

NOMURA, H., NIELSEN, B.W., and MATSUSHIMA, K. (1993). Molecular cloning of cDNAs encoding a LD78 receptor and putative leukocyte chemotactic peptide receptors. Int. Immunol. 5, 1239-1249.

PROBST, W.B., SNYDER, L.A., SCHUSTER, D.I., BROSIUS, J., and SEALFON, S.C. (1992). Sequence alignment of the G protein-coupled-receptor superfamily. DNA Cell Biol. 11, 1-20.

ROSENBERG, H.F., TENEN, D.G., and ACKERMAN, S.J. (1989). Molecular cloning of the human eosinophil-derived neurotoxin: a member of the ribonuclease gene family. Proc. Natl. Acad. Sci. USA 86, $4460-4464$.

Address reprint requests to: Dr. Philip M. Murphy The Laboratory of Host Defenses NIAID, Bldg. 10, Rm. 11 NI13 National Institutes of Health Bethesda, MD 20892

Received for publication February 9, 1995; accepted April 27, 1995. 